Macedonian Pharmaceutical Bulletin, 66 (Suppl 1) 195 - 196 (2020)

Online ISSN 1857 - 8969

UDC: 615.47:006.83

DOI: 10.33320/maced.pharm.bull.2020.66.03.097

Short communication

\title{
ISO 14971:2019 - Implication to the medical devices manufacturer's quality system with emphasis of post - production activities
}

\author{
Marija Davcheva Jovanoska ${ }^{1}$, Elizabeta Karadzinska ${ }^{1}$, Nada Popstefanova ${ }^{1}$, \\ Olivera Paneva ${ }^{1}$, Suzana Trajkovic Jolevska ${ }^{2}$, Jasmina Tonic Ribarska ${ }^{2}$, Jelena Lazova ${ }^{1}$, \\ Elena Ivanovska ${ }^{1}$ \\ ${ }^{1}$ Pharmaceutical Chemical Cosmetic Industry ALKALOID AD Skopje, Blvd. Aleksandar Makedonski 12, \\ 1000 Skopje, Republic of North Macedonia \\ ${ }^{2}$ Faculty of Pharmacy, Ss Cyril and Methodius University, Str. Majka Tereza 47, \\ 1000 Skopje,Republic of North Macedonia
}

\section{Introduction}

Historically, risk management has been a complex subject, with different stakeholders assigning different values on the probability and severity of harm. In medical devices, its high importance has necessitated ISO 14971 Application of risk management for medical devices, providing a generic risk-management framework applicable to all medical devices, from design and development through production and postproduction activities. In December 2019, the new updated version of the ISO 14971 was released. What does this update mean to medical devices manufacturer's quality system? A transitional period of three years allows manufacturers to successfully implement the new requirements in their quality system.

Relationship between ISO 14971:2019 and Medical Device Regulation (MDR)

Manufacturers of medical devices have a major challenge ahead of adapting the quality management system to meet the new requirements of ISO 14971:2019 and MDR. It is a mitigating circumstance that the new ISO 14971 is better aligned with the general safety and performance requirements of the MDR (Council of Europe, 2017; ISO, 2019). While no major changes have been made to the overall process of how to conduct riskmanagement, manufacturers will need to spend some time examining the details associated with each change in the new standard to ensure that the quality system is completely aligned with each requirement.

More requirements for production and postproduction activities

Manufacturers of medical devices should comply with requirements of ISO 14971 for production and post - production activities from ISO 14971 and the MDR. The MDR talks about a risk management process, ISO 14971 about a risk management system. Production and post production activities include four phases, each with detailed activities to be properly implemented in the system:

\footnotetext{
*mdavceva1@alkaloid.com.mk
} 
1. Establish a system to collect and review information from production and post market activities

2. Collect relevant information for the medical device (i.e., information from users, distributors, publicly available information, literature, etc.).

3. Review the information gathered in phase 2 to determine its relevance to device safety. Any previously unidentified hazards or hazardous situations, new risks, or significant changes affecting the risk need to be assessed to determine if a new benefit-risk assessment is warranted.

4. Implement actions by reviewing the risk management file to determine whether new risks need to be assessed or previous risks require reassessment. This phase also includes determining whether actions are necessary for devices already on the market and assessing the impact of previous risk management activities. Additional risk control measures may need to be implemented (ISO, 2019; Trevino, 2019; van Vroonhoven, 2019).

The policy for establishing criteria for risk acceptability and the resulting criteria must take general safety and performance requirements into account, meaning for example that risks must be reduced as far as possible as long as it does not adversely affect the benefit risk ratio. The new standard specifies requirements for production and post-production information to be considered as part of the overall risk assessment process throughout the life of the device. Both the MDR and the $3^{\text {rd }}$ edition of ISO 14971 require proactive collection and evaluation of data from post-development phases that must be properly included in manufacturer's quality system. The principles of collecting and reviewing information have not changed, but the requirements and the activities are described more elaborately and more precisely (Council of Europe, 2017; ISO, 2019; Trevino, 2019).

\section{Conclusion}

ISO 14971:2019 provides a thorough process for manufacturers to identify medical device hazards, assess risks, control risks, and monitor the effectiveness of risk controls throughout the life of a device. This new edition is aligned with the general safety and performance requirements within the new EU MDR. It is now impossible to image that a medical device would be developed and placed on the market without thorough risk assessment or without post-production monitoring.

While the existing changes are aimed at clarifying concepts and no changes have been made to the overall process to conduct risk management, manufacturers still need to consider device-specific standards. These can be used - in addition to ISO 14971 - to control specific risks associated with some unique device categories to demonstrate how risks can be reduced to acceptable levels using the data from production and post - production activities. It is anticipated that some manufacturers of medical devices will have to spend some time updating references to the previous standard in existing quality system documentation.

Risk management is a challenging process in the industry, and in our view, these changes aim to clarify and simplify requirements. The end goal should be to improve the effectiveness of the risk management process to consistently launch highly beneficial, safe and effective medical products by proper implementation of the requirements for production and post - production activities in the manufacturer's quality system.

\section{References}

Council of Europe, 2017. Regulation (EU) 2017/745 of the European Parliament and of the Council of 5 April 2017 on medical devices, amending Directive 2001/83/EC, Regulation (EC) No 178/2002 and Regulation (EC) No 1223/2009 and repealing Council Directives 90/385/EEC and 93/42/EEC. Official Journal of the European Union. L 117, 1175.

ISO 14971:2019 Medical devices - Application of risk management to medical devices. International standard

Trevino, M., 2019. Analyzing The Changes To Risk Management Standard ISO 14971:2019. Guest column. Med Device online. Available at:

https://www.meddeviceonline.com/doc/analyzingthe-changes-to-risk-management-standard-iso-0001.

van Vroonhoven, J., 2019. Risk management for medical devices and the new ISO 14971. Available at: https://www.bsigroup.com/globalassets/meddev/ localfiles/fr-fr/whitepapers/ risk management web. pdf (Last accessed on 01.03.2020).

Maced. Pharm. Bull. 66 (Suppl 1) 195 - 196 (2020) 